\title{
Small RNA expression and miRNA modification dynamics in human oocytes and early embryos
}

\author{
Pauliina Paloviita, ${ }^{1}$ Christel Hydén-Granskog, ${ }^{2}$ Dawit A. Yohannes, ${ }^{1}$ Priit Paluoja, ${ }^{3}$ \\ Juha Kere, ${ }^{4,5,6}$ Juha S. Tapanainen, 1,2,7,8 Kaarel Krjutškov, ${ }^{3,5,9}$ Timo Tuuri, $^{1,2}$ \\ Urmo Võsa, ${ }^{10}$ and Sanna Vuoristo ${ }^{1}$ \\ ${ }^{1}$ University of Helsinki, Department of Obstetrics and Gynecology, 00014, Helsinki, Finland; ${ }^{2}$ Helsinki University Hospital, \\ Department of Obstetrics and Gynecology, 00029, Helsinki, Finland; ${ }^{3}$ Competence Centre for Health Technologies, 50411, Tartu, \\ Estonia; ${ }^{4}$ Karolinska Institutet, Department of Biosciences and Nutrition, 14152, Huddinge, Sweden; ${ }^{5}$ Stem Cells and Metabolism \\ Research Program, University of Helsinki, 00014, Helsinki, Finland; ${ }^{6}$ Folkhälsan Research Center, 00290, Helsinki, Finland; \\ ${ }^{7}$ Department of Obstetrics and Gynecology, University of Oulu, 90014, Oulu, Finland; ${ }^{8}$ Oulu University Hospital, Medical Research \\ Centre, PEDEGO Research Unit, 90029, Oulu, Finland; ${ }^{9}$ Institute of Clinical Medicine, Department of Obstetrics and Gynecology, \\ University of Tartu, 50406, Tartu, Estonia; ${ }^{10}$ Estonian Genome Center, Institute of Genomics, University of Tartu, 51010 , \\ Tartu, Estonia
}

\begin{abstract}
Small noncoding RNAs (sRNAs) play important roles during the oocyte-to-embryo transition (OET), when the maternal phenotype is reprogrammed and the embryo genome is gradually activated. The transcriptional program driving early human development has been studied with the focus mainly on protein-coding RNAs, and expression dynamics of sRNAs remain largely unexplored. We profiled sRNAs in human oocytes and early embryos using an RNA-sequencing (RNAseq) method suitable for low inputs of material. We show that OET in humans is temporally coupled with the transition from predominant expression of oocyte short piRNAs (os-piRNAs) in oocytes, to activation of microRNA (miRNA) expression in cleavage stage embryos. Additionally, $3^{\prime}$ mono- and oligoadenylation of miRNAs is markedly increased in zygotes. We hypothesize that this may modulate the function or stability of maternal miRNAs, some of which are retained throughout the first cell divisions in embryos. This study is the first of its kind elucidating the dynamics of sRNA expression and miRNA modification along a continuous trajectory of early human development and provides a valuable data set for indepth interpretative analyses.
\end{abstract}

[Supplemental material is available for this article.]

\begin{abstract}
Mammalian oocytes and embryos express three major classes of small noncoding RNAs (sRNAs): Piwi-interacting RNAs (piRNAs), endogenous small interfering RNAs (endo-siRNAs), and miRNAs (Suh and Blelloch 2011). In animals, miRNAs are processed into 22-nt-long functional units by sequential DROSHA/DGCR8 and DICER1 cleavage of hairpin structures embedded in long transcripts. miRNAs associate with argonaute proteins (AGO) to form the RNA-induced silencing complex (RISC) and mediate gene silencing via binding to partially complementary elements in the $3^{\prime}$ untranslated region of target mRNAs, resulting in mRNA deadenylation and/or inhibition of translation (Bartel 2018). piRNAs are transcribed from hundreds of genomic clusters into primary transcripts that are cleaved by PLD6 (a homolog of Zucchini endoribonuclease) (Ozata et al. 2019). PIWI proteins bind piRNA intermediates that are further trimmed to lengths of $\sim 26-30 \mathrm{nt}$ and finally 2'-O-methylated by HENMT1 at their $3^{\prime}$ termini (Weick and Miska 2014). These conventional piRNAs are found primarily in germ cells, where they regulate gene expression and repress transposons (Aravin et al. 2006; Grivna et al. 2006; Lau et al. 2006; Watanabe et al. 2008). Recently, a novel sRNA class, oocyte short piRNAs (os-piRNAs), was found as highly abundant in human and primate oocytes and two-cell embryos and absent
\end{abstract}

Corresponding author: sanna.vuoristo@helsinki.fi

Article, supplemental material, and publication date are at https://www. genome.org/cgi/doi/10.1101/gr.268193.120. in murine oocytes (Yang et al. 2019). os-piRNAs are 20 nt long, specifically associate with PIWIL3, and are likely to mediate the silencing of recently evolved transposable elements. The predominant expression of os-piRNAs and low abundance of endo-siRNAs (Yang et al. 2019) in human oocytes and two-cell embryos suggests a partial divergence of primates from other animals in sRNA-mediated regulation of early development.

Embryo stage-specific miRNA expression and miRNA-mediated degradation of maternal transcripts during OET has been reported in multiple organisms (Giraldez et al. 2006; Bushati et al. 2008; Lund et al. 2009; Mondou et al. 2012). In mice, maternal miRNAs undergo degradation upon fertilization, zygotic miRNAs are up-regulated from the two-cell stage onward, and miRNA-mediated degradation of maternal transcripts is suggested to initiate in subsequent cleavage stages (Ohnishi et al. 2010; Yang et al. 2016). Depletion experiments of either Ago2, Dicer1, or Dgcr8 in mouse oocytes and zygotes have further substantiated the requirement of an intact conventional piRNA and endo-siRNA biogenesis pathway in normal oocyte development and miRNA pathway in later embryonic development (Bernstein et al. 2003; Morita et al.

\footnotetext{
(C) 2021 Paloviita et al. This article is distributed exclusively by Cold Spring Harbor Laboratory Press for the first six months after the full-issue publication date (see https://genome.cshlp.org/site/misc/terms.xhtml). After six months, it is available under a Creative Commons License (AttributionNonCommercial 4.0 International), as described at http://creativecommons. org/licenses/by-nc/4.0/.
} 
2007; Murchison et al. 2007; Tang et al. 2007; Kaneda et al. 2009; Suh et al. 2010; Stein et al. 2015; Taborska et al. 2019). Despite the reports on temporal interspecies differences in miRNA-mediated regulation of maternal transcripts (Giraldez et al. 2006; Ohnishi et al. 2010), many homologous miRNAs are abundant in both human and other mammalian embryos (McCallie et al. 2010; Rosenbluth et al. 2013), indicating partial conservation of miRNA expression and miRNA-mediated regulation of normal development and reproduction in animals.

Novel sRNA-seq technologies enable cell level dissection of miRNA expression profiles, identification of novel miRNAs, and miRNA sequence isoforms (isomiRs). IsomiRs are generated by alternative DROSHA or DICER1 cleavage, RNA editing, or nontemplated nucleotide addition (tailing) and can differ from their canonical mature miRNA forms in length, sequence, or both (Landgraf et al. 2007; Neilsen et al. 2012; Gebert and MacRae 2019). Recently, isomiRs have gained widespread attention in the context of OET as prominent miRNA $3^{\prime}$ end adenylation (A-tailing) and low-level miRNA $3^{\prime}$ end uridylation (U-tailing) has been reported in early Drosophila, sea urchin, and mouse embryos (Fernandez-Valverde et al. 2010; Lee et al. 2014; Yang et al. 2016). To date sRNAs have not been sequenced in human developmental stages coinciding with embryo genome activation (EGA), the initiation of embryonic transcription, that peaks at the eightcell stage and overlaps with the clearance of maternal transcripts (Tesarik et al. 1987; Braude et al. 1988; Töhönen et al. 2015). To investigate stage-specific changes in sRNA distributions and elucidate the role of miRNAs and their isoforms in early human development, we sequenced sRNAs in consecutive developmental stages, from human germinal vesicle (GV) oocytes to eight-cell embryos. To our knowledge this is the first report of sRNA sequencing along a continuous trajectory of early human development.

\section{Results}

\section{Expression of sRNA biogenesis pathway components}

The biogenesis of multiple sRNAs depends on DICER1-mediated cleavage of precursor RNAs (Song and Rossi 2017). Different sRNA biogenesis pathways also include class-specific factors, such as DGCR8 in the case of miRNAs. Because miRNA function has been proposed to be suppressed during early development (Ma et al. 2010; Suh et al. 2010; García-López and del Mazo 2012; Kataruka et al. 2020), we asked whether DGCR8 and DICER1 are expressed at the protein level in the human cleavage stage embryos. We immunostained human four- and eight-cell embryos with monoclonal antibodies raised against DGCR8 and DICER1. DGCR8 was found in the nuclei and DICER1 was predominantly present in the cytoplasm of four- $(n=3)$ and eightcell stage embryos $(n=2)$ (Fig. $1 \mathrm{~A})$, as expected (Ha and Kim 2014). These results suggest that both the microprocessor complex and DICER1 are present in human cleavage stage embryos; however, it remains unexplored whether the expression levels are sufficient for generation of miRNAs. miRNA biogenesis and function also require the cellular presence of precursor miRNA modifying protein, DROSHA, and function-regulating AGO proteins. We analyzed published human oocyte and preimplantation embryo single cell RNA-seq (scRNA-seq) data (Yan et al. 2013) and detected DROSHA, DICER1, and DGCR8 expression throughout development, with first significant changes in expression levels occurring at the four-cell stage (FDR $<0.05$, Wilcoxon rank-sum test, two-sided) (Fig. 1B). Expression of $A G O$ class genes (AGO1-4) found in mammals was detected throughout preimplantation development, except for $A G O 4$ that had low overall mRNA levels. Of the $A G O$ genes, $A G O 2$ showed earliest differences in expression levels, namely, up-regulation at four-cell stage (FDR $<0.05$, Wilcoxon rank-sum test, two-sided), and had highest overall expression, as is common also in differentiated mammalian tissues (Gebert and MacRae 2019). piRNA pathway genes, PLD6, HENMT1, and PIWIL1-4, were expressed at comparable levels to miRNA pathway genes (Fig. 1C). PLD6 expression resembled the expression pattern of DGCR8, whereas HENMT1 was highly expressed until the eightcell stage, where it became down-regulated (FDR $<0.05$, Wilcoxon rank-sum test, two-sided). PIWIL1-3 genes were down-regulated at the eight-cell stage and continued to decline as development proceeded (FDR $<0.05$, Wilcoxon rank-sum test, two-sided), whereas PIWIL4 expression was almost absent in all stages.

\section{Identification of sRNA classes in human oocytes and embryos}

To investigate sRNA expression in early human development, we sequenced single human oocytes, zygotes, and early embryos. sRNA sequencing libraries $(n=27)$ were prepared from GV $(n=6)$, Metaphase I (MI; $n=3$ ), and Metaphase II (MII; $n=3$ ) oocytes, zygotes (two-pronuclear zygote [2PN] $n=2$; three-pronuclear zygote [3PN] $n=3)$, and four- $(n=5)$ and eight-cell $(n=5)$ embryos (Fig. 2A; Supplemental Fig. S1). We used sRNAbench (Rueda et al. 2015; Aparicio-Puerta et al. 2019) with human miRBase (v22) (Kozomara et al. 2019), Ensembl cDNA (hg38), Ensembl noncoding RNA (hg38), and RNAcentral version 14 (hg38) databases, and os-piRNA sequence information (Yang et al. 2019) to map and annotate sRNAs that have been previously identified (Supplemental Fig. S2). Classification of sRNAs depends on the reliability of the databases used and previous sequence information reported. In this study, the identification of endo-siRNAs was not included in the preprocessing, which may result in overlap of some of the studied sRNA classes. The samplewise average mapping percentage and number of quality and read length filtered genome mapped reads was $82 \%$ and $\sim 2$ million, respectively (Supplemental Table S1A). We analyzed sRNA classes that are or produce functional fragments of 17-30 nt in length. The length distribution of sRNA reads showed a single modal pattern in oocytes and zygotes, with a peak centered around $20 \mathrm{nt}$ (Fig. 2B; Supplemental Fig. S3A). In embryos, this peak was less prominent and had an elongated right tail. miRNAs and recently described os-piRNAs (Yang et al. 2019) accounted for $\sim 4 \%-8 \%$ of mapped reads, in the range of 20-24 nt. os-piRNAs and miRNAs were centered around 20 and $23 \mathrm{nt}$, respectively. Shorter sRNA reads (17-19 nt) mainly mapped to os-piRNAs, mitochondrial tRNAs (mt-tRNAs), and ribosomal RNAs (rRNAs). Variation in the relative abundance of sRNA classes was observed between samples of the same developmental stages, likely owing to biological interindividual differences, variation in embryo division kinetics, and technical factors (Fig. 2C).

For downstream analyses we focused on miRNAs, os-piRNAs, and conventional piRNAs. Detected os-piRNAs and conventional piRNAs had a $1 \mathrm{U}$ and $10 \mathrm{~A}$ base composition preference, in line with previous observations (Supplemental Fig. S3B; Yang et al. 2019). Conventional piRNAs and os-piRNAs were located primarily in intergenic regions that were mainly nonrepeat elements and in lesser numbers LINE or LTR-associated regions (Supplemental Fig. S4A,B). miRNAs were primarily derived from coding sequence introns and noncoding exons, and the few intergenic miRNAs were located in repeat associated regions (Fig. 2D; Supplemental Fig. S4C). We performed principal component analysis 
A

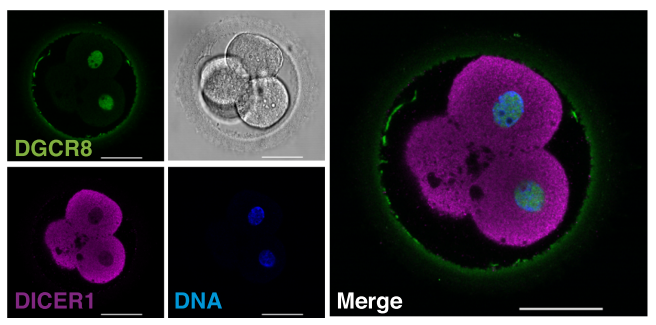

4-cell embryo
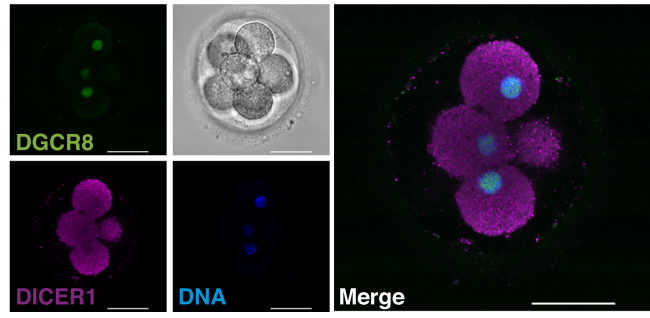

8-cell embryo

B
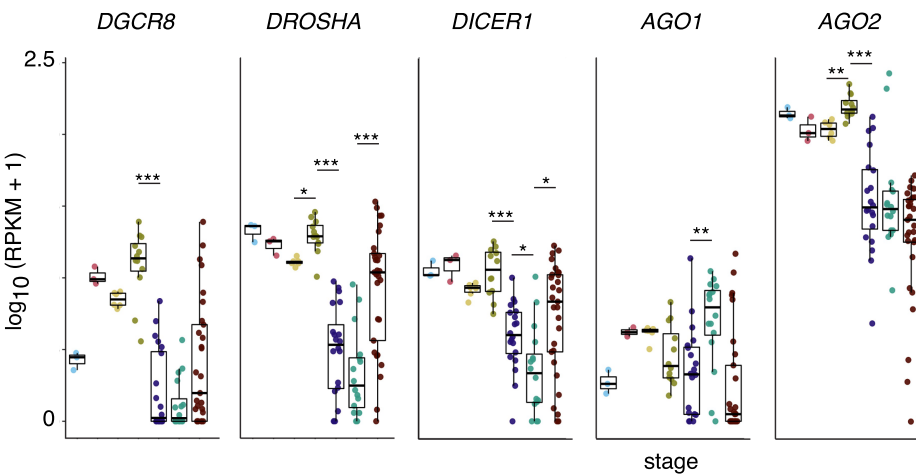

AGO3

AGO4

C
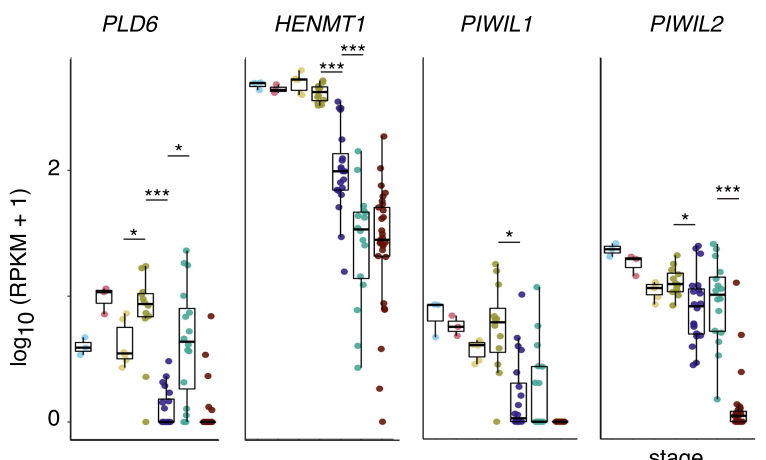

PIWIL3
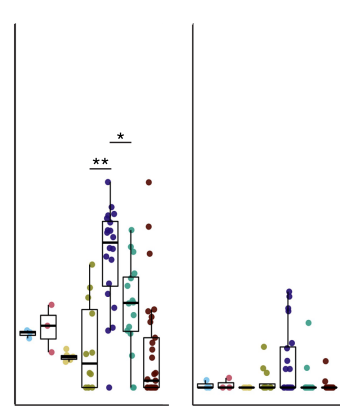

stage

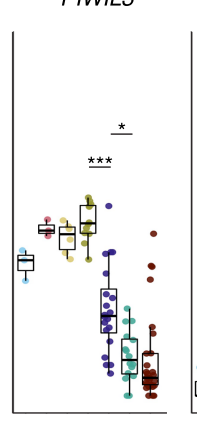

PIWIL4

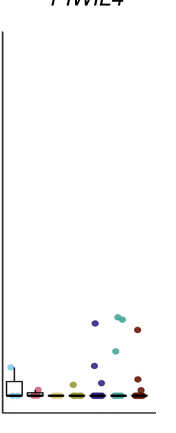

stage

oocyte

zygote

2-cell

4-cell

- 8-cell

morula

- blastocyst

Figure 1. Small RNA (sRNA) pathway component expression in human oocytes and embryos. (A) Human four-cell (left) and eight-cell (right) embryos immunostained with DGCR8 (green) and DICER1 (magenta) antibodies. Nuclei are counterstained with DAPI (blue). Overlay of a single representative zplane and the corresponding $z$-planes are shown. Nucleus and bright field channels are on the right side of each overlay. Scale bar is $50 \mu \mathrm{m}$. Expression levels (RPKM) in human oocytes and preimplantation embryos (Yan et al. 2013): (B) miRNA pathway gene, DGCR8, DROSHA, DICER1, and ACO1-4; (C) piRNA pathway gene, PLD6, HENMT1, and PIWIL1-4. (B,C) Significant expression changes between consecutive developmental stages were assessed using pairwise, two-sided Wilcoxon rank-sum tests: $(*)$ FDR $<0.05 ;\left(^{* *}\right)$ FDR $<0.01 ;\left({ }^{* *}\right)$ FDR $<0.001$. The horizontal line in the box plot indicates the expression median.

(PCA) of our samples separately for miRNAs, os-piRNAs, and conventional piRNAs (Supplemental Fig. S5) including sRNAs that were detected ( $>0$ reads) in at least three samples (Supplemental Table S1B). Before batch-adjustment the samples clustered according to sequencing batch and by developmental stage within the two batches. When adjusting the data for the batch (Law et al. 2014; Ritchie et al. 2015), samples clustered by developmental stage, with clearest stagewise separation between oocytes and embryos, for miRNAs and conventional piRNAs, and oocytes, zygotes, and embryos for os-piRNAs. The aforementioned groupings were used in some of the downstream analyses to detect robust changes between different developmental stages. Furthermore, samples of the same developmental stage showed good reproducibility in miRNA expression (Supplemental Fig. S6). We analyzed changes of total miRNA, os-piRNA, and conventional piRNA levels between oocytes, zygotes, and embryos using the Kruskal-Wallis test and pairwise, two-sided Wilcoxon rank-sum test. We could not account for batch effect in these analyses because of the absence of a factorial two-way nonparametric test. Embryos differed in os-piRNA expression from oocytes and zygotes, and in conventional piRNA expression from oocytes $(F D R<0.05)$, whereas for miRNAs the expression difference between oocytes and embryos was not significant $(F D R=0.054)$. As previously reported, os-piRNAs levels were abundant in oocytes (Yang et al. 2019) and slightly lower in cleavage stage embryos (Fig. 2E) with the conventional piRNAs following a similar expression pattern, although at lower overall abundances. As we analyzed reads of maximum length of $30 \mathrm{nt}$, some conventional piRNAs that are typically 26-32 nt in length (Williams et al. 2015) may have been excluded. miRNA levels seemed to increase during oocyte maturation, decrease modestly in zygotes, and were at highest levels in eight-cell stage embryos, possibly indicating the beginning of miRNA synthesis from the embryo's own genome.

\section{Genome Research}

www.genome.org 
A
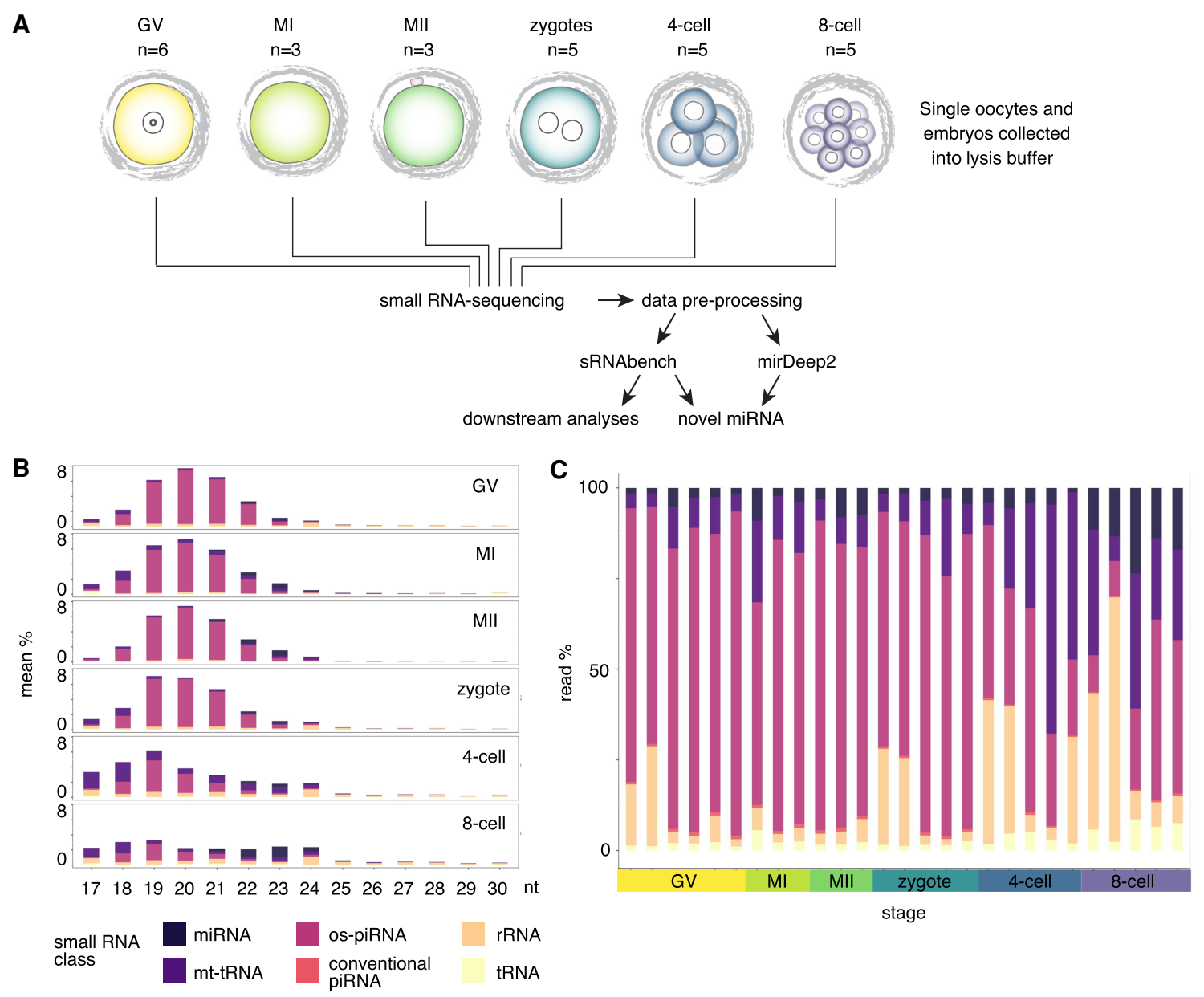

D

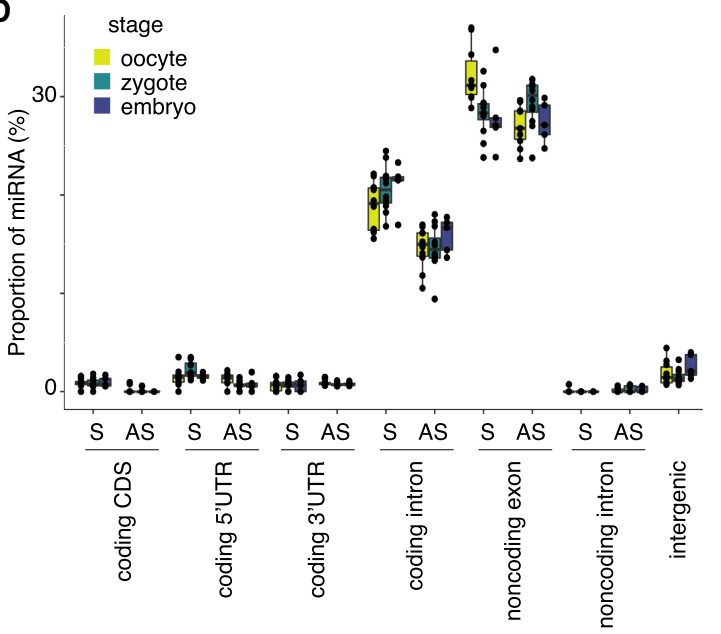

E

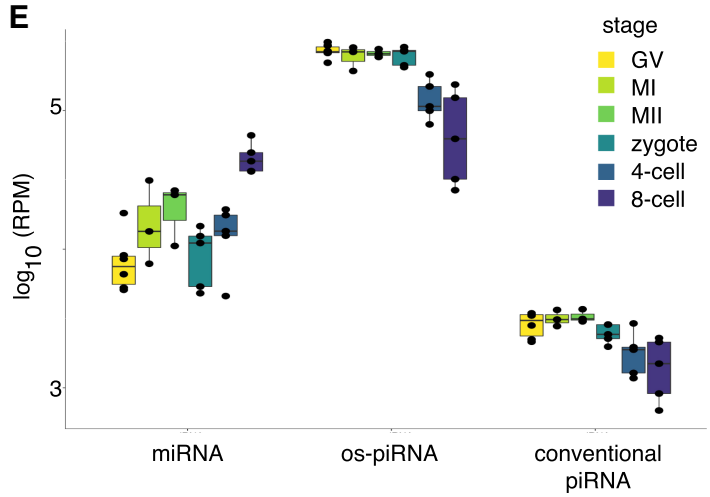

Figure 2. Categories of sRNAs. (A) Schematic of the study design. We sequenced sRNAs in human oocytes, zygotes, and embryos and did downstream analyses using sRNAbench (Aparicio-Puerta et al. 2019; Rueda et al. 2015) and miRDeep2 v0.1.2 (Friedländer et al. 2012). (GV) Germinal vesicle oocyte ( $n=$ 6); (MI) Metaphase I oocyte $(n=3)$; (MII) Metaphase II oocyte $(n=3)$; zygote $(n=5)$; (4-cell) four-cell embryo $(n=5)$; $(8$-cell) eight-cell embryo $(n=5)$. ( $B)$ sRNA class expression at different nucleotide lengths (17-30 nt) in the oocyte maturation stages, zygotes, and cleavage stage embryos. Stagewise mean proportion of reads mapped to different sRNA classes are shown. (miRNA) microRNA; (mt-tRNA) mitochondrial tRNA; (os-piRNA) oocyte short piRNA; (conventional piRNA) Piwi-interacting RNA; (rRNA) ribosomal RNA; (tRNA) transfer RNA. (C) Proportion of different sRNAs class reads in samples. The samples are grouped according to developmental stage and separated by sample number. (D) Proportion of miRNAs derived from different genomic elements at each developmental stage. (E) miRNA, os-piRNA, and conventional piRNA expression (reads per million [RPM]) in early human developmental stages. Embryos $(n=10)$ differed in os-piRNA expression from oocytes $(n=12)$ and zygotes $(n=5)$, and in conventional piRNA expression from oocytes $(F D R<0.05$ Wilcoxon rank-sum test, two-sided), whereas for miRNAs the expression difference between oocytes and embryos was not significant $(F D R=0.054)$. $(D, E)$ The horizontal line in the box plot indicates the median value. 


\section{miRNA expression during oocyte-to-embryo development}

miRNAs represented $<2 \%$ of mapped reads in human oocytes, zygotes, and embryos, thus constituting a minor sRNA population present during human early embryonic development, as reported also in other organisms (Alberti and Cochella 2017; Kataruka et al. 2020). We observed considerable variation in the miRNA repertoire of the samples: of 2707 human miRNAs in miRBase v22, 471 and 260 were detected ( $>0$ mapped reads) in at least one and three samples, respectively (Supplemental Table S2). This subset of 260 miRNAs was analyzed in subsequent steps. The majority (70\%) of the miRNAs were expressed across all the developmental stages, indicating subtle changes in cellular miRNA species composition during OET (Fig. 3A). We identified miRNAs that were consistently abundant during human OET by extracting the top 35 miRNAs according to expression median and detection in $>80 \%$ of samples (Fig. 3B). Expression clustering of these miRNAs revealed a subset of highly abundant miRNAs that included members of the embryonic stem cell-specific miRNome (hsa-miR-371a-3p, hsamiR-371a-5p, hsa-miR-372-3p, and hsa-miR-373-3p) (Suh et al. 2004; Houbaviy et al. 2005; Landgraf et al. 2007; Babiarz et al. 2008) and miRNAs previously found to be abundant in human oocytes and embryos (hsa-miR-148a, hsa-miR-7-5p, miR-509-3-5p, and hsa-miR-92a-3p) (Rosenbluth et al. 2013; Yang et al. 2019). Many of these miRNAs are conserved between species and expressed during early murine development (Supplemental Fig. S7A; Tang et al. 2007; Ohnishi et al. 2010; Yang et al. 2016), suggesting partial conservation in cellular miRNA composition during OET in humans and other mammals.

Next, we investigated whether miRNA expression changes occurred during the reprogramming of the maternal oocyte to the totipotent zygote and early embryo phenotype (Jukam et al. 2017; Torres-Padilla 2020). We detected 21 differentially expressed (DE) miRNAs between oocytes $(n=12)$ and embryos $(n=10$; FDR <0.05) (Fig. 3C; Supplemental Fig. S7B; Supplemental Table S3). We constructed an expression-clustered heatmap of the DE miRNAs (Fig. 3D) and observed that hsa-miR-6821 and hsa-miR$664 \mathrm{~b}-5 \mathrm{p}$ were mainly detected in oocytes and prominently down-regulated in embryos, whereas expression changes of other down-regulated miRNAs were subtler. Up-regulated miRNAs, hsamiR-519b-5p, hsa-miR-363-3p, hsa-miR-629-5p, hsa-miR-375-3p, and hsa-miR-1307-3p were detected mainly after the zygote stage and may represent paternally inherited miRNAs (detected in human sperm cells) (Hua et al. 2019) or some of the first miRNAs transcribed from the embryo's genome. The miR-25/32/92/363/367 family members (hsa-miR-92b-3p, hsa-miR-25-3p, and hsa-miR363-3p) that share the same seed sequence and some target RNAs were also among the up-regulated miRNAs. Altogether, the scarcity of miRNA expression level changes during human OET suggests that many maternal miRNAs are passed from oocyte to zygote and retained at least for the duration of the first cleavage divisions in human embryos.

\section{miRNA modification dynamics in human OET}

Posttranscriptional modification of miRNAs, especially miRNA 3 ' adenylation, has been described in the early development of several model organisms (Fernandez-Valverde et al. 2010; Lee et al. 2014; Yang et al. 2016). We investigated miRNA 5' and 3' prime length variation $(\mathrm{lv})$, length variation of both ends (multiple length variation $[\mathrm{mv}])$, and $3^{\prime}$ end tailing modifications in human oocytes, zygotes, and embryos using sRNAbench (Aparicio-Puerta et al. 2019) for miRNA isoform detection (Fig. 4A). Notably, 3' end truncation and A-tailing were the most abundant modifications across studied stages. Additions of single (mono) and multiple (oligo) nucleotides of the same base were aggregated for the primary analyses. We detected 456 different isomiRs ( $>0$ mapped reads, in at least three samples) (Supplemental Table S4) of which $>60 \%$ were found in all studied stages. Consistently highly abundant isomiRs that we identified based on the data-set-wide expression median in the top $20 \%$ and detection in more than $80 \%$ of samples were mainly $3^{\prime}$ end lv or A-tailing isoforms (Supplemental Fig. $\mathrm{S} 8 \mathrm{~A}$ ). We further investigated isomiR expression differences between oocytes $(n=12)$ and embryos $(n=10)$ and found $41 \mathrm{DE}$ isomiRs $(F D R<0.05)$ (Supplemental Table S5). The DE isomiRs formed three groups when clustered according to expression (Fig. 4B). Two groups consisted of multiple A-tailed miRNAs that were up-regulated beyond the zygote stage and length-modified miRNAs that became down-regulated in zygotes or embryos formed the third group. Modifications of the same type, especially of the miRNA 3 ' end, were found in multiple consistently highly expressed and DE isomiRs, suggesting coordinated, widespread miRNA modification during human OET.

To investigate overall changes in miRNA modifications during early human development, we aggregated miRNA reads with the same modification and normalized them over the total of miRNA mapped reads within samples. We studied changes in miRNA modifications between oocytes $(n=12)$ and embryos $(n=10)$ using a linear model to account for sequencing batch. A majority of the studied miRNA modification ratios differed between oocytes and embryos (FDR < 0.05) (Supplemental Table S6) with A-tailing showing the largest expression magnitude differences. We compared Atailing to other tailing modifications by analyzing stagewise mean modification ratios across the developmental trajectory. A-tailing was at low-levels ( $~ 5 \%)$ in oocytes, rapidly increased to $\sim 20 \%$ in zygotes, and gradually decreased in cleavage stage embryos $(\sim 15 \%)$ (Fig. 4C). U-tailing occurred at lower levels and in an inverse pattern to that of A-tailing, and nontemplated addition of $\mathrm{C}$ and $\mathrm{G}$ nucleotides was infrequent throughout development. TENT2, TENT4B, and MTPAP mediate A-tailing, and TUT7, TUT4, and TUT1 mediate U-tailing of miRNAs in humans (Jones et al. 2009; Katoh et al. 2009; Burroughs et al. 2010; Wyman et al. 2011). In human oocytes and embryos, A-tailing factors were more highly expressed than U-tailing factors $(F D R<0.01$, paired Wilcoxon signed-rank test, two-sided), suggesting higher potency for sRNA $3^{\prime}$ adenylation than uridylation during early development (Supplemental Fig. S8B). As suggested by the isomiR DE analysis, modification of multiple miRNA species explained the increased A-tailing in zygotes (Fig. 4D). A-tailing occurred in an inverse manner to detection of canonical miRNA reads across samples (Supplemental Fig. S8C). A- and Utailing mainly occurred as single nucleotide additions (Fig. 4E; Supplemental Fig. S8D). Low-leveled monoadenylation of miRNA 3 ' ends was present and steadily increasing already in oocytes, whereas oligoadenylation commenced from the zygote stage onward. It is conceivable that the difference in modification lengths may indicate the existence of different miRNA A-tailing means in human oocytes and zygotes. To identify miRNAs contributing most to the observed overall A- and U-tailing levels, we applied filters on stagewise isomiR mean ratios $(>0.33)$ and read medians $(>1000)$. IsomiR ratios represent the proportion of isomiR reads over the corresponding miRNA species read total. The overall miRNA A- and U-tailing levels were mainly explained by 20 and six different isomiRs, respectively (Fig. 4F; Supplemental Fig. $\mathrm{S} 8 \mathrm{E})$, with nucleotide addition lengths following the global modification trends (Supplemental Fig. S8F, G). A majority of the highly

\section{Genome Research}

www.genome.org 


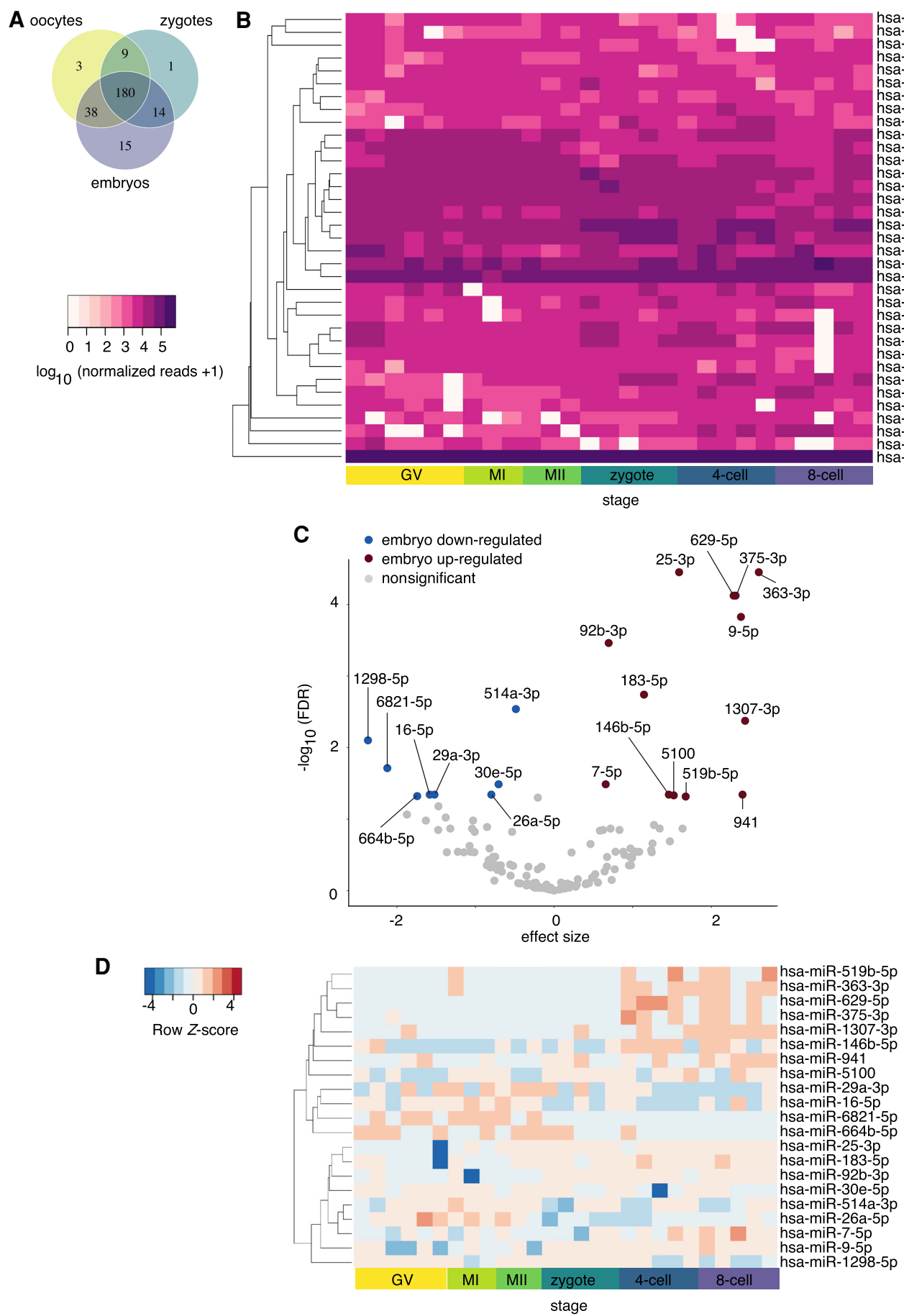

Figure 3. miRNA expression in human oocytes and embryos. (A) Venn diagram of miRNA species (260 in total) that are shared or uniquely expressed in human oocytes $(n=12)$, zygotes $(n=5)$, and embryos $(n=10)$. (B) Heatmap of miRNAs with highest expression levels (top 35 according to median, observations in $>80 \%$ of samples) across samples. (C) FDR and effect size of the 21 differentially expressed (DE; FDR $<0.05)$ miRNAs between oocytes and embryos according to MACAU 2.0 (Sun et al. 2017). (D) Heatmap of DE miRNA row Z-scores. ( $B, D)$ Euclidean distance and average linkage were used to cluster miRNAs by expression.

A-tailed isomiRs were conserved miRNA species, and approximately half were DE (FDR < 0.05) between oocytes and embryos. Because A-tailing may affect global miRNA stability (Burroughs et al. 2010; Marzi et al. 2016), we compared stagewise means of A-tailing ratios and normalized reads for each miRNA species (Supplemental Fig.
S9A). We applied cutoffs to visualize A-tailed miRNAs (stagewise isomiR mean ratio $>0.05$ ), in the top or lower $5 \%$ of sample-wide normalized reads and found several miRNAs with moderate to high A-tailing ratios and high expression levels across several stages of development. We did not observe a clear correlation between 
A

\begin{tabular}{l|rrrrrc}
\multicolumn{1}{c|}{ Modification } & GV & MI & MII & zygote & 4-cell & 8 -cell \\
& 3.1 & 4.9 & 6.7 & 23.3 & 21.1 & 14.5 \\
$\mathrm{nta}^{*} \mathrm{~A}$ & 0.4 & 0.5 & 0.3 & 0.8 & 0.6 & 0.4 \\
$\mathrm{nta}^{\star} \mathrm{C}$ & 0.1 & 0.2 & 0.2 & 0.9 & 0.7 & 0.8 \\
$\mathrm{nta}{ }^{\star} \mathrm{G}$ & 3.7 & 3.4 & 3.3 & 2.2 & 2.0 & 1.3 \\
$\mathrm{nta}{ }^{*} \mathrm{U}$ & 4.3 & 4.2 & 4.0 & 4.0 & 3.3 & 5.3 \\
5' trimmed (Iv5pT) & 0.7 & 0.8 & 0.9 & 0.6 & 0.5 & 0.4 \\
5' elongated (Iv5pE) & 12.4 & 13.8 & 14.7 & 13.6 & 11.4 & 9.5 \\
3' trimmed (Iv3pT) & 8.8 & 4.8 & 5.3 & 5.7 & 7.0 & 6.2 \\
3' elongated (IV3pE) & & & & & & \\
multiple lenght & 2.3 & 3.4 & 2.6 & 2.7 & 3.2 & 2.0 \\
variants (mv) & & & & & &
\end{tabular}

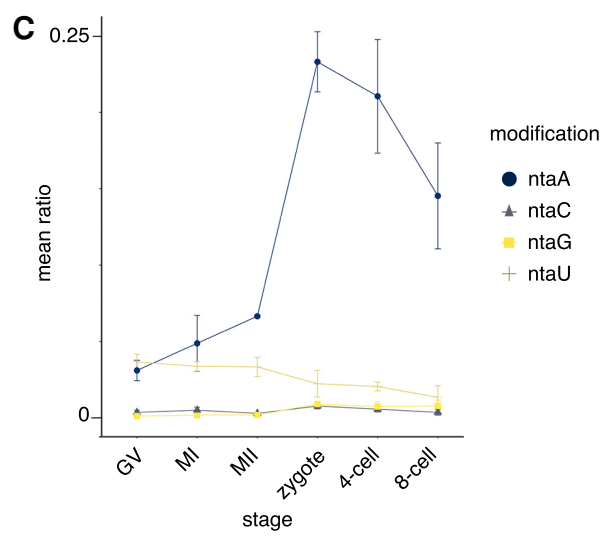

B

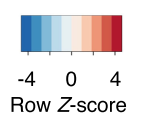

Row Z-score

modification
$\mathrm{ntaA}$
$\mathrm{ntaC}$
$\mathrm{ntaG}$
$\mathrm{ntaU}$
Iv3pE
Iv3pT
Iv5pE
Iv5pT
$\mathrm{mv}$
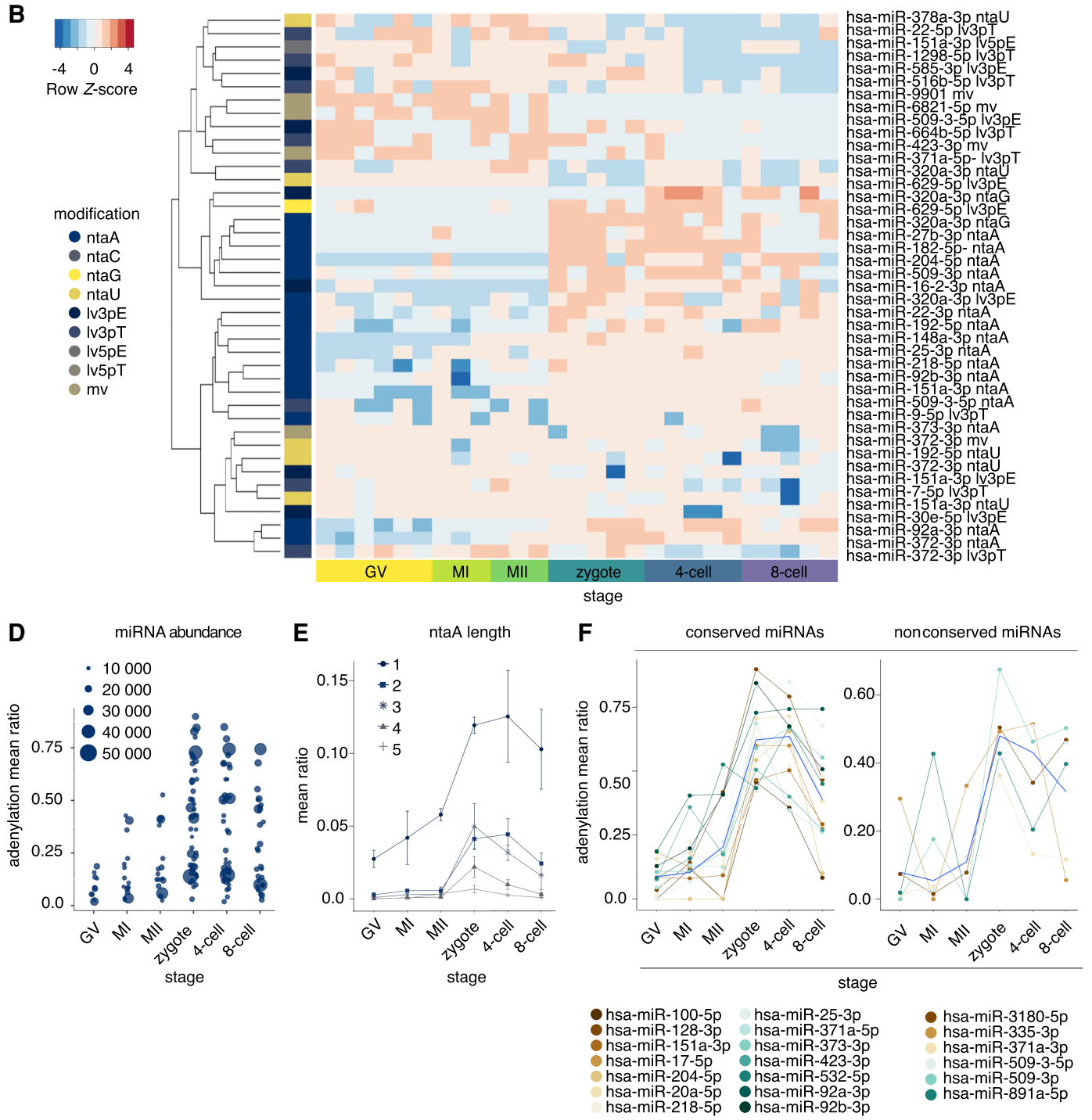

Figure 4. Dynamic miRNA $3^{\prime}$ tailing in human oocytes and early embryos. (A) miRNA modification mean proportions in different developmental stages. (B) Heatmap of DE $(F D R<0.05)$ miRNA modification isoforms (isomiRs) according to MACAU 2.0 (Sun et al. 2017). Euclidean distance and average linkage were used to cluster isomiRs (see $A$ for nomenclature) by expression, presented as row Z-scores. (C) miRNA $3^{\prime}$ nontemplated nucleotide addition of A, C, G, and $\mathrm{U}$ in different developmental stages. miRNA $3^{\prime}$ adenylation (A-tailing) is frequent in zygotes and early embryos. (D) miRNA A-tailing ratio of 50 miRNA species (mean normalized reads greater than 500 in at least one stage). Size of the circle indicates the stagewise mean of the normalized miRNA abundance. (E) miRNA A-tailing modification length in different developmental stages. Modification lengths of up to $5 \mathrm{nt}$ are shown. Addition of a single nucleotide was the predominant modification. $(F)$ A-tailing dynamics of conserved and nonconserved miRNAs with highest A-tailing ratios (mean normalized reads greater than 1000 and mean ratio above 0.33 in at least one stage). Locally estimated scatterplot smoothing (loess) curve (blue) resembled the overall A-tailing modification trend. Mean stagewise miRNA modification ratio $(C-F)$ and the $95 \%$ confidence interval $(C, E, F)$ are shown.

\section{Genome Research}

www.genome.org 
A-tailing and miRNA abundance in human oocytes, zygotes, or embryos. Further analysis of the DE miRNAs revealed that miRNAs down-regulated in embryos were less often A-tailed than the miRNAs up-regulated in embryos (Supplemental Fig. S9B). Although A-tailing of miRNAs is associated with both miRNA stabilization (Katoh et al. 2009; Yang et al. 2016) and degradation (Ameres et al. 2010; Lee et al. 2014; de la Mata et al. 2015) depending on the miRNA and context, our data suggest that A-tailing may stabilize specific maternal miRNAs during human OET, contributing to their transmission from the oocyte to the developing embryo.

\section{Identification of novel miRNAs}

In addition to previously annotated mature miRNAs, the sRNA-seq approach allowed us to identify nine putative novel miRNAs that were detected by both sRNAbench (Aparicio-Puerta et al. 2019) and mirDeep2 (Friedländer et al. 2012). Two of these miRNAs met the majority of miRBase high confidence criteria and additional requirements outlined in Fromm et al. (2015) (Table 1; Supplemental Fig. S10A). Both of the quality filtered putative premiRNA sequences originated from genomic locations that are conserved across primates and represent intergenic regions with the other pre-miRNA located within a LINE element. Only a subset of the analyzed samples expressed each novel miRNA, with oocytes most prominently represented (Supplemental Fig. S10B).

\section{Discussion}

Here, we have for the first time sequenced the sRNA repertoire in sequential early human developmental stages, from GV oocytes to cleavage stage embryos, enabling us to detect sRNAs and their modifications. We identified changes in miRNA and isomiR expression patterns and identified two putative novel miRNAs. Limitations of the study include suboptimal read data quantification owing to absence of UMIs or ERCC spike-ins in the sequencing libraries and small sample size. Improved sRNA-seq library preparation methods coupled with increased sequencing depth would enable better coverage and detection of lowly expressed sRNA classes. Future studies are required to extend our findings using improved sRNA-seq methods and larger sample size. However, our study provides valuable and novel insight on sRNA regulation during human OET.

The sRNA composition of human oocytes and early embryos differs from their mammalian counterparts, in which endo-siRNAs dominate instead of primate-specific os-piRNAs (Suh and Blelloch 2011; García-López et al. 2014; Yang et al. 2019). os-piRNA expression was stable and abundant during oocyte maturation and started to decrease in cleavage stage embryos, anticipating the complete loss of expression, at the morula stage (Yang et al. 2019). It is possible that identification of conventional piRNAs and os-piRNAs based on clusters during preprocessing, as in Yang et al. (2019), may expand these classes. In our data, global miRNA levels were relatively low and rather stable across human oocyte maturation, suggesting differences in the accumulation of maternal miRNAs compared to that of mRNAs, which are highly abundant and stored in ribonucleoprotein complexes during oogenesis (Nakamura et al. 2001; Richter and Lasko 2011; ChristouKent et al. 2020). Indeed, the low expression levels of maternal miRNAs and resulting limited regulatory function has been observed in oocytes of several organisms (Kataruka et al. 2020). Dgcr8-lacking mouse oocytes and zygotes develop until the blastocyst stage (Ma et al. 2010; Suh et al. 2010) or arrest around the time of gastrulation, respectively, indicating the requirement for an active miRNA biogenesis pathway in cellular lineage commitment and cell specification (Bernstein et al. 2003; Suh et al. 2010). We observed highest miRNA levels in eight-cell-stage embryos, implying that miRNA biogenesis, and thereby also function, may gradually initiate in the early embryo stages. All cleavage embryo upregulated miRNAs were conserved between animals, and several cause abnormal phenotypes including infertility, developmental defects, or even embryonic lethality upon knockout of the miRNA homolog or its family member in mouse (Shibata et al. 2011; Penzkofer et al. 2014; Han et al. 2015; Ahmed et al. 2017). We suggest that OET in humans entails a switch from maternally predominant os-piRNAs to embryonic miRNAs, coinciding with EGA, as has been reported for mouse (Bouniol et al. 1995; Tang et al. 2007; Yang et al. 2016). It will be interesting to further investigate the dispensability of different sRNA pathways at different steps of human early embryonic development.

We observed widespread miRNA modification, namely A-tailing, and partial miRNA clearance in human zygotes. We observed the trend toward decreased miRNA abundance in zygotes compared to MI and MII oocytes and a majority of the detected miRNAs were shared with oocytes, suggesting their maternal inheritance. A-tailing of miRNAs peaked prominently at the zygote stage and reduced in subsequent embryonic stages. Three of five zygotes had three pronuclei, however it is unclear whether this affects global miRNA and modification levels. Nevertheless, a largescale clearance of maternal miRNAs occurs in mice around the

Table 1. Sequence and conservation information of the identified putative novel pre-miRNAs

\begin{tabular}{|c|c|c|c|c|c|c|}
\hline $\begin{array}{l}\text { Precursor } \\
\text { candidate }\end{array}$ & Sequence $^{a}$ & $\begin{array}{l}\text { Reads } \\
5 p / 3 p\end{array}$ & $\begin{array}{l}\text { Length } \\
\text { (nt) }\end{array}$ & $\begin{array}{l}\text { Genomic } \\
\text { coordinates } \\
\text { (GRCh38) }\end{array}$ & $\begin{array}{l}\text { Location } \\
\text { description }\end{array}$ & $\begin{array}{c}\text { Genomic } \\
\text { conservation }\end{array}$ \\
\hline pre-mir-REF_37481 & $\begin{array}{l}\text { 5'-GTCTGGCCACGTTTTGGTAGAGGAGCTGTGCT } \\
\text { GGGGGATTTCTITCACTCCCAGTCAG } \\
\text { TGTGGACTCTTCAAAGCCCACAGGCTGA-3' }\end{array}$ & $234 / 21$ & 86 & $\begin{array}{l}\text { Chr 6: } \\
\text { 40,055,688- } \\
\text { 40,055,773; } \\
\text { Strand: - }\end{array}$ & $\begin{array}{l}\text { Intergenic, } \\
\text { LINE }\end{array}$ & Primates \\
\hline pre-mir-REF_29581 & $\begin{array}{l}\text { 5'-AGTATCTAAGACCCCAGGTAATAGTAAGACACT } \\
\text { ATTAATAGAGCCCAAGCGTCTTACTATTACTTGGG } \\
\text { CTGTGACTAAGTAAT-3 }\end{array}$ & $108 / 4988$ & 83 & $\begin{array}{l}\text { Chr 4: } \\
77,254,597- \\
77,254,679 \\
\text { Strand: + }\end{array}$ & Intergenic & Primates \\
\hline
\end{tabular}

Sequence of the putative pre-miRNA and reads mapping to the corresponding miRNA 5p and 3p arms were predicted and assigned by sRNAbench. Samplewise total and miRNA mapped reads are shown in Supplemental Table S1A. Genomic conservation was assessed visually with MULTIZ Alignments track (default 100 vertebrate species) of the UCSC Genome Browser.

${ }^{\mathrm{a}}$ Mature sequence underlined; star sequence bold. 
one-cell (zygote) to four-cell stage (Tang et al. 2007; Yang et al. 2016), and prominent maternal miRNA A-tailing has been reported in multiple organisms, with species-specific differences in highest modification ratios ranging from mature oocytes to developmental stages around EGA (Fernandez-Valverde et al. 2010; Lee et al. 2014; Yang et al. 2016). We identified eight down-regulated miRNAs in embryos, some of which were completely lost at the zygote stage. Yet many maternally inherited miRNAs, both conserved and nonconserved miRNA family members, were retained at stable expression levels throughout early human development. In mice oligoadenylation is suggested to protect miRNAs from the clearance of maternal miRNAs (Yang et al. 2016). We did not observe clear correlation between miRNA A-tailing levels and abundance. Furthermore, miRNA synthesis from the embryo genome may have partially masked global effects of A-tailing on maternal miRNA stability. We observed abundant expression levels for multiple highly A-tailed miRNAs in consecutive developmental stages, alike to several previous reports (Fernandez-Valverde et al. 2010; Yang et al. 2016). Among the frequently A-tailed miRNAs were members of the conserved miR-25/32/92/363/367 seed family that were also highly expressed throughout early human development. This miRNA family is also A-tailed in two- and four-cell mouse embryos (Yang et al. 2016), and partial embryonic lethality has been observed in murine knockout studies of individual or multiple of its family members (Bartel 2018). A-tailing was observed in 66\% of the detected miRNA species, both conserved and nonconserved, and Atailed isoforms represented more than $75 \%$ of reads for some miRNAs at the zygote stage, emphasizing the variability and selectivity in A-tailing of different miRNAs during human OET. The total increase in zygotic A-tailing was explained by both mono- and oligoadenylation, and adenylation length may provide yet an additional layer of miRNA regulation. Our data suggest that similar to murine early development (Tang et al. 2007; Ohnishi et al. 2010; Yang et al. 2016), many maternally inherited miRNAs avoid the clearance of maternal transcripts during human OET and may even be selectively stabilized by A-tailing in zygotes, ensuring their availability in later embryonic stages, where they are likely to contribute to normal development.

TENT2 presumably carries out the majority of miRNA A-tailing in early development (Neilsen et al. 2012) and is also expressed in human oocytes, zygotes, and embryos (Yan et al. 2013). However, the involvement of multiple cofactors and enzymes in the regulation of timing, rate, and selectivity of miRNA A-tailing is likely and may affect outcomes (Kai and Pasquinelli 2010). It is intriguing to speculate that A-tailing could simultaneously stabilize and modulate functions of maternal retained miRNAs, for instance, by interfering with miRNA incorporation into RISC (Liu et al. 2004; Meister et al. 2004). Recent studies report that miRNAs mediate transcriptional activation in differentiated cells (Place et al. 2008; Zhang et al. 2014), translational activation of target mRNAs in frog oocytes and fly embryo extracts (Iwasaki and Tomari 2009; Mortensen et al. 2011), and sequester target transcripts via phase transition (Sheu-Gruttadauria and MacRae 2018). The aforementioned functions remain largely unexplored in relation to miRNA modifications and mammalian development, calling for further studies on regulation of miRNA A-tailing, and its possible implications on miRNA-mediated mechanisms during OET. Future work is imperative to understand the mechanisms regulating the reprogramming of the maternal sRNA profile as well as confirming whether, when, and how miRNAs function during early embryonic development in humans.

\section{Methods}

\section{Ethics approval and informed consent}

Collection and experiments on human oocytes and embryos were approved by the Helsinki University Hospital ethical committee, diary number HUS/1069/2016. Research permission was approved by the Helsinki University Hospital research committee. Human surplus oocytes, zygotes, and embryos were donated by couples that had undergone infertility treatments at Helsinki University Hospital Reproduction Medicine Unit. The samples were donated with an informed consent, and patients understood that donating oocytes, zygotes, or embryos is voluntary.

\section{Collection of human oocytes and embryos}

Immature oocytes from intracytoplasmic sperm injection (ICSI) cycles as well as fertilized oocytes (3PN zygotes), surplus zygotes, and embryos were donated for research by signing an informed consent. GV oocytes were collected at the time of denudation, about 1-2 $\mathrm{h}$ after ovum pick-up. MI oocytes were collected at the time of ICSI, 2-4 h after ovum pick-up. MII oocytes were left in culture for an additional 2-4 h (5-7 h after ovum pick-up). Zygotes and embryos had been cryopreserved by slow freezing (PROH) at the time of in vitro fertilization (IVF)/ICSI-treatment. 2PN zygotes had been cryopreserved $18-20 \mathrm{~h}$ after insemination or ICSI. Zygotes were thawed and collected for library preparation $\sim 2 \mathrm{~h}$ after thawing. 3PN zygotes were collected 18-20 h after insemination (IVF). Four-cell embryos had been cryopreserved 43-45 h after insemination or ICSI. Embryos of 7-9 cells (day 3) had been cryopreserved $67-69 \mathrm{~h}$ after insemination or ICSI. Embryos were thawed and collected 1-3 $\mathrm{h}$ after thawing.

\section{Immunocytochemistry and confocal imaging of human embryos}

Fixed human embryos were immunostained with antibodies for DGCR8 (clone 3F5, MA5-24860) and DICER (clone CL0378, MA5-31353) (both from Thermo Fisher Scientific) as previously (Reichhardt et al. 2019) and detailed in Supplemental Methods. The images were captured using a Leica TCS SP8 confocal laser scanning microscope (Leica Systems), with HC PL APO CS2 40X/ 1.10NA water objective. Images were processed using Fiji (https ://fiji.sc). The representative single $z$-plane images were smoothened using a Gaussian filter (radius $=1$ pixel kernel).

\section{Sequencing library preparation}

sRNA-seq library preparation was performed using NEBNext Small RNA Library Prep Set for Illumina kit (New England Biolabs [NEB]) with the following modifications. The samples were rinsed in $\mathrm{Ca}_{2}^{+} /$ $\mathrm{Mg}_{2}^{+}$-free PBS and placed in $3 \mu \mathrm{L}$ of lysis buffer containing $5 \mathrm{mM}$ Tris- $\mathrm{HCl}$ at $\mathrm{pH} 7.5$ (Sigma-Aldrich); 0.1\% Tween-20 (SigmaAldrich); $50 \mathrm{mM} \mathrm{KCl} \mathrm{(Sigma-Aldrich),} \mathrm{and} 2.5$ units of RiboLock RNase inhibitor (Thermo Fisher Scientific). One microliter of 1:3 diluted 3' SR Adapter (NEB), $1 \mu \mathrm{L}$ of $0.5 \mathrm{M} \mathrm{KCl}, 1 \mu \mathrm{L}$ of $20 \mu \mathrm{M} 5 \mathrm{~S}$ and 5.8S rRNA masking oligo mixture, and $1 \mu \mathrm{L}$ of nuclease-free water was added to samples. The samples were incubated in a thermal cycler for $1 \mathrm{~min}$ at $90^{\circ} \mathrm{C}$ and at for $2 \mathrm{~min} 60^{\circ} \mathrm{C}$ to mask the rRNA. Three microliters of $3^{\prime}$ ligation enzyme mix (NEB) and $10 \mu \mathrm{L}$ of $3^{\prime}$ adapter ligation reaction buffer (NEB) was added to samples. The samples were incubated for $60 \mathrm{~min}$ at $25^{\circ} \mathrm{C}$. To the samples we added $4.5 \mu \mathrm{L}$ of nuclease-free water and $1 \mu \mathrm{L}$ of $1: 3$ diluted SR RT Primer (NEB). The libraries were incubated for $5 \mathrm{~min}$ at $75^{\circ} \mathrm{C}$, for $15 \mathrm{~min}$ at $37^{\circ} \mathrm{C}$, and for $15 \mathrm{~min}$ at $25^{\circ} \mathrm{C}$. The $5^{\prime} \mathrm{SR}$ adapter (NEB) was resuspended in nuclease-free water (1:3) and denaturated by incubation for $2 \mathrm{~min}$ at $70^{\circ} \mathrm{C}$. One microliter of denatured $5^{\prime}$ SR adapter (NEB), $1 \mu \mathrm{L}$ of $10 \times$ ligation reaction buffer (NEB), and $2.5 \mu \mathrm{L}$ of $5^{\prime}$ ligase

\section{Genome Research}

www.genome.org 
enzyme mix (NEB) were added to samples. The samples were incubated for $60 \mathrm{~min}$ at $25^{\circ} \mathrm{C}$. Eight microliters of First Strand Synthesis buffer (NEB), $1 \mu \mathrm{L}$ of Murine RNase inhibitor (NEB), and $1 \mu \mathrm{L}$ of ProtoScript II Reverse Transcriptase (NEB) were added to samples. The libraries were incubated for $60 \mathrm{~min}$ at $50^{\circ} \mathrm{C}$ and for $10 \mathrm{~min}$ at $75^{\circ} \mathrm{C}$. The cDNA pool $(40 \mu \mathrm{L})$ was purified using NucleoSpin Gel and PCR Clean up Columns for gel extraction and PCR clean up (Macherey-Nagel) according to PCR product purification protocol and eluted in $30 \mu \mathrm{L}$ elution buffer. To the purified cDNA mixture we added $30 \mu \mathrm{L} 2 \times$ Phusion Hot MasterMix (Thermo Fisher Scientific) and $1 \mu \mathrm{L}$ of each $100 \mu \mathrm{M}$ primer, universal primer, and barcoded primer. The following PCR was performed: initial denaturation and activation $1 \mathrm{~min}$ at $98^{\circ} \mathrm{C}$, cycle denaturation $10 \mathrm{sec}$ at $98^{\circ} \mathrm{C}$, annealing $20 \mathrm{sec}$ at $62^{\circ} \mathrm{C}$, extension $5 \mathrm{sec}$ at $70^{\circ} \mathrm{C}$, and a final extension $5 \mathrm{~min}$ at $72^{\circ} \mathrm{C}$. Nineteen cycles were performed. PCR product $(80 \mu \mathrm{L})$ was purified in same manner as the cDNA pool and eluted in $25 \mu \mathrm{L}$ elution buffer. Small PCR fragments were removed by adding $28 \mu \mathrm{L}$ AMPureXP beads (Beckman), mixing, and incubating $10 \mathrm{~min}$ at room temperature. Beads were captured by magnet and the supernatant was removed. The pellet was resuspended in $30 \mu \mathrm{L}$ nuclease-free water, placed back on the magnet, and the clear supernatant, ready sRNA library, was transferred to a tube. The library was quantified by KAPA SYBR FAST qPCR kit (Roche) according to instructions. The sRNA library was sequenced using an Illumina MiSeq (Illumina) instrument. The detailed proto$\mathrm{col}$, and oligo and primer sequences are provided in Supplemental Methods and Supplemental Table S7, respectively.

\section{Preprocessing of sRNA-seq data}

We performed preprocessing of the raw sRNA-seq reads and the expression profiling of sRNAs using sRNAbench (Rueda et al. 2015; Aparicio-Puerta et al. 2019). Sequence reads that contained at least the first $10 \mathrm{nt}$ of the adapter sequence were adapter trimmed, and reads of sizes 17-30 nt were kept. We used the genome mode approach for expression profiling (Rueda et al. 2015). Briefly, the preprocessed reads were aligned using Bowtie (Langmead et al. 2009) to the human genome (GRCh38, primary assembly from Ensembl) allowing one mismatch, and further mapped successively to the following databases: human miRBase (v22) (Kozomara et al. 2019), Ensembl cDNA (hg38), Ensembl noncoding RNA (hg38), RNAcentral version 14 (hg38), and os-piRNA (Yang et al. 2019). Unassigned reads were aligned to the human genome (GRCh38) to detect novel miRNAs. To evaluate the distribution of miRNAs, piRNAs, and os-piRNAs across genomic elements we used BEDTools 2.29.0 (Quinlan and Hall 2010) and GENCODE v23 (hg38) genome annotations resembling analyses by Yang et al. (2019). sRNAs were assigned to coding CDS, 5'-UTR, 3'-UTR, intron, and noncoding exon and intron, successively. Intergenic sRNAs were intersected with LINE, LTR, SINE, DNA, and other repeats, and flanking regions of $0-1 \mathrm{~kb}$ and $1-2 \mathrm{~kb}$ to assess their distribution in repetitive elements. Detailed information is provided in Supplemental Methods.

\section{sRNA, miRNA, and isomiR expression}

Reads mapped to different sRNA classes were normalized over the total of library mapped reads within the sample. Maximum values of single assignment reads provided by sRNAbench were extracted for each miRNA or isomiR within the sample to overcome errors arising from multimapping reads. Each miRNA species represents the aggregated canonical mature form and isomiR reads. Reads mapping to different miRNA species were normalized over the samplewise total of miRNA mapped reads. IsomiR reads were normalized with two independent methods: in the same manner as
miRNAs and by samplewise scaling of isomiR reads over corresponding miRNA species total reads. Detection of more than zero reads in at least three samples was required for miRNAs and isomiRs to be included in downstream analyses.

\section{Differential expression analyses}

Several samples included in the study were genetically related because they were donated by the same individual or couple. To account for sample relatedness, we used R package MACAU 2.0 v1.10 (Sun et al. 2017) in DE analysis of miRNAs and isomiRs. Oocytes $(n=12)$ were compared to embryos $(n=10)$ using the Poisson mixed model in MACAU 2.0. We required each miRNA/ isomiR to have more than one read in at least five samples after adding a pseudocount of 1 to be included in the analysis. miRNA modification ratio differences between oocytes and embryos were determined using a linear model with the modification ratio as the response variable and batch and phenotype as the explanatory variables. Phenotype variable $P$-values were extracted from each model and adjusted for multiple testing using the Benjamini-Hochberg method (Benjamini and Hochberg 1995). Expression changes were regarded as significant when FDR $<$ 0.05. Detailed information is provided in Supplemental Methods.

\section{Novel miRNAs}

We predicted novel miRNAs with miRDeep2 v0.1.2 (Friedländer et al. 2012) and sRNAbench (Rueda et al. 2015; Aparicio-Puerta et al. 2019) as specified in Supplemental Methods. Briefly, detection of novel miRNAs was performed using unassigned reads that were 17-25 nt long. Mature human miRNA and hairpin sequences from miRBase $\mathbf{v} 22$ were provided to detect reads mapping to known miRNAs. Mature miRNAs of all other available species were used to detect novel miRNAs with annotated miRNA homologs. We required a $>90 \%$ overlap of pre-miRNA coordinate predictions by both software and expression of putative miRNA and/or star sequence in more than one sample with more than zero reads assigned by sRNAbench. The novel (pre-)miRNA candidates were further investigated for their confidence based on miRBase high confidence criteria (Kozomara and Griffiths-Jones 2014) and additional quality criteria stated in Fromm et al. (2015).

\section{Data access}

The data set that supports these findings has been deposited with CSC-IT Center for Science Ltd., and it is accessible for scientific purposes at https://doi.org/10.24340/x3z4-rpmfwx. Because of patient consent and confidentiality agreements, data access will be evaluated by the Data Access Committee according to Finnish legislation. Data can be accessed internationally with valid Data Access Agreement, but data processing is restricted to Finland. To initiate the data access application process, contact servicedesk@csc.fi (e-mail subject: SD Apply/Sensitive Data).

\section{Competing interest statement}

The authors declare no competing interests.

\section{Acknowledgments}

We thank the couples that donated their surplus oocytes, zygotes, or embryos for this project and the in vitro fertilization (IVF) nurses at the Reproduction Medicine Unit of the Helsinki University Hospital for recruiting the couples. We thank Dr. Giuliano Stirparo, Dr. Alberto Pessia, and Dr. Ari Löytynoja for insightful discussions 
and Karolina Lundin for language editing. We acknowledge Biostatistics consulting, from the Department of Public Health, at the University of Helsinki and Helsinki University Hospital for discussions on statistical matters, Biomedicum Imaging Unit (Helsinki) for skilled technical assistance, and CSC-IT Center for Science Ltd. for supercomputing. The study was supported by grants from Jane and Aatos Erkko Foundation and Sigrid Jusélius Foundation to J.S.T., S.V., and J.K., Academy of Finland (295760) and Helsinki University Hospital Funds to J.S.T., and the Doctoral Programme in Biomedicine to P. Paloviita.

Author contributions: Conceptualization, S.V., U.V., and J.K.; sample collection, C.H.-G.; library preparation, S.V. and K.K.; data-preprocessing and sRNA location analyses, D.A.Y. and P. Paluoja; bioinformatic and statistical analyses, P. Paloviita; supervision, S.V. and T.T; writing-original draft, P. Paloviita; writing —review and editing, P. Paloviita, S.V.; acquired funding, S.V, J.S.T., and J.K. All authors were involved in editing and accepted the final version of the manuscript.

\section{References}

Ahmed K, LaPierre MP, Gasser E, Denzler R, Yang Y, Rülicke T, Kero J, Latreille M, Stoffel M. 2017. Loss of microRNA-7a2 induces hypogonadotropic hypogonadism and infertility. J Clin Invest 127: 1061-1074. doi:10.1172/JCI90031

Alberti C, Cochella L. 2017. A framework for understanding the roles of miRNAs in animal development. Development 144: 2548-2559. doi:10 $.1242 /$ dev.146613

Ameres SL, Horwich MD, Hung JH, Xu J, Ghildiyal M, Weng Z, Zamore PD. 2010. Target RNA-directed trimming and tailing of small silencing RNAs. Science 328: 1534-1539. doi:10.1126/science.1187058

Aparicio-Puerta E, Lebrón R, Rueda A, Gómez-Martín C, Giannoukakos S, Jaspez D, Medina JM, Zubkovic A, Jurak I, Fromm B, et al. 2019 sRNAbench and sRNAtoolbox 2019: intuitive fast small RNA profiling and differential expression. Nucleic Acids Res 47: W530-W535. doi:10 .1093/nar/gkz415

Aravin A, Gaidatzis D, Pfeffer S, Lagos-Quintana M, Landgraf P, Iovino N Morris P, Brownstein MJ, Kuramochi-Miyagawa S, Nakano $T$, et al. 2006. A novel class of small RNAs bind to MILI protein in mouse testes. Nature 442: 203-207. doi:10.1038/nature04916

Babiarz JE, Ruby JG, Wang Y, Bartel DP, Blelloch R. 2008. Mouse ES cells express endogenous shRNAs, siRNAs, and other Microprocessor-independent, Dicer-dependent small RNAs. Genes Dev 22: 2773-2785. doi:10 $.1101 /$ gad.1705308

Bartel DP. 2018. Metazoan microRNAs. Cell 173: 20-51. doi:10.1016/j.cell .2018 .03 .006

Benjamini Y, Hochberg Y. 1995. Controlling the false discovery rate: a practical and powerful approach to multiple testing. J R Stat Soc Ser B $\mathbf{5 7}$ 289-300. doi:10.1111/j.2517-6161.1995.tb02031.x

Bernstein E, Kim SY, Carmell MA, Murchison EP, Alcorn H, Li MZ, Mills AA, Elledge SJ, Anderson KV, Hannon GJ. 2003. Dicer is essential for mouse development. Nat Genet 35: 215-217. doi:10.1038/ng1253

Bouniol C, Nguyen E, Debey P. 1995. Endogenous transcription occurs at the 1-cell stage in the mouse embryo. Exp Cell Res 218: 57-62. doi:10 1006/excr.1995.1130

Braude P, Bolton V, Moore S. 1988. Human gene expression first occurs between the four- and eight-cell stages of preimplantation development. Nature 332: 459-461. doi:10.1038/332459a0

Burroughs AM, Ando Y, de Hoon MJL, Tomaru Y, Nishibu T, Ukekawa R, Funakoshi T, Kurokawa T, Suzuki H, Hayashizaki Y, et al. 2010. A comprehensive survey of $3^{\prime}$ animal miRNA modification events and a possible role for $3^{\prime}$ adenylation in modulating miRNA targeting effectiveness. Genome Res 20: 1398-1410. doi:10.1101/gr.106054.110

Bushati N, Stark A, Brennecke J, Cohen SM. 2008. Temporal reciprocity of miRNAs and their targets during the maternal-to-zygotic transition in Drosophila. Curr Biol 18: 501-506. doi:10.1016/j.cub.2008.02.081

Christou-Kent M, Dhellemmes M, Lambert E, Ray PF, Arnoult C. 2020. Diversity of RNA-binding proteins modulating post-transcriptional regulation of protein expression in the maturing mammalian oocyte. Cells 9: 662. doi:10.3390/cells9030662

de la Mata M, Gaidatzis D, Vitanescu M, Stadler MB, Wentzel C, Scheiffele P, Filipowicz W, Großhans H. 2015. Potent degradation of neuronal miRNAs induced by highly complementary targets. EMBO Rep 16: 500-511. doi:10.15252/embr.201540078
Fernandez-Valverde SL, Taft RJ, Mattick JS. 2010. Dynamic isomiR regulation in Drosophila development. RNA 16: 1881-1888. doi:10.1261/rna 2379610

Friedländer MR, Mackowiak SD, Li N, Chen W, Rajewsky N. 2012. miRDeep2 accurately identifies known and hundreds of novel microRNA genes in seven animal clades. Nucleic Acids Res 40: 37-52. doi:10.1093/nar/gkr688

Fromm B, Billipp T, Peck LE, Johansen M, Tarver JE, King BL, Newcomb JM, Sempere LF, Flatmark K, Hovig E, et al. 2015. A uniform system for the annotation of vertebrate microRNA genes and the evolution of the human microRNAome. Annu Rev Genet 49: 213-242. doi:10.1146/ annurev-genet-120213-092023

García-López J, del Mazo J. 2012. Expression dynamics of microRNA biogenesis during preimplantation mouse development. Biochim Biophys Acta Gene Regul Mech 1819: 847-854. doi:10.1016/j.bbagrm.2012.03.007

García-López J, Hourcade JdD, Alonso L, Cárdenas DB, del Mazo J. 2014 Global characterization and target identification of piRNAs and endosiRNAs in mouse gametes and zygotes. Biochim Biophys Acta - Gene Regul Mech 1839: 463-475. doi:10.1016/j.bbagrm.2014.04.006

Gebert LFR, MacRae IJ. 2019. Regulation of microRNA function in animals. Nat Rev Mol Cell Biol 20: 21-37. doi:10.1038/s41580-018-0045-7

Giraldez AJ, Mishima Y, Rihel J, Grocock RJ, Van Dongen S, Inoue K, Enright AJ, Schier AF. 2006. Zebrafish MiR-430 promotes deadenylation and clearance of maternal mRNAs. Science 312: 75-79. doi:10.1126/sci ence. 1122689

Grivna ST, Beyret E, Wang Z, Lin H. 2006. A novel class of small RNAs in mouse spermatogenic cells. Genes Dev 20: 1709-1714. doi:10.1101/ gad.1434406

Ha M, Kim VN. 2014. Regulation of microRNA biogenesis. Nat Rev Mol Cell Biol 15: 509-524. doi:10.1038/nrm3838

Han Y, Vidigal JA, Mu P, Yao E, Singh I, González AJ, Concepcion CP, Bonetti C, Ogrodowski P, Carver B, et al. 2015. An allelic series of miR-17 92-mutant mice uncovers functional specialization and cooperation among members of a microRNA polycistron. Nat Publ Gr 47: 766-775. doi:10.1038/ng.3321

Houbaviy HB, Dennis L, Jaenisch R, Sharp PA. 2005. Characterization of a highly variable eutherian microRNA gene. RNA 11: 1245-1257. doi:10 $.1261 /$ rna.2890305

Hua M, Liu W, Chen Y, Zhang F, Xu B, Liu S, Chen G, Shi H, Wu L. 2019. Identification of small non-coding RNAs as sperm quality biomarkers for in vitro fertilization. Cell Discov 5: 20. doi:10.1038/s41421-0190087-9

Iwasaki S, Tomari Y. 2009. Argonaute-mediated translational repression (and activation). Fly (Austin) 3: 205-208. doi:10.4161/fly.3.3.9025

Jones MR, Quinton LJ, Blahna MT, Neilson JR, Fu S, Ivanov AR, Wolf DA, Mizgerd JP. 2009. Zcchc11-dependent uridylation of microRNA directs cytokine expression. Nat Cell Biol 11: 1157-1163. doi:10.1038/ncb1931

Jukam D, Shariati SAM, Skotheim JM. 2017. Zygotic genome activation in vertebrates. Dev Cell 42: 316-332. doi:10.1016/j.devcel.2017.07.026

Kai ZS, Pasquinelli AE. 2010. MicroRNA assassins: factors that regulate the disappearance of miRNAs. Nat Struct Mol Biol 17: 5-10. doi:10.1038/ nsmb.1762

Kaneda M, Tang F, O'Carroll D, Lao K, Surani MA. 2009. Essential role for Argonaute2 protein in mouse oogenesis. Epigenetics Chromatin 2: 9. doi:10.1186/1756-8935-2-9

Kataruka S, Modrak M, Kinterova V, Malik R, Zeitler DM, Horvat F, Kanka J, Meister G, Svoboda P. 2020. MicroRNA dilution during oocyte growth disables the microRNA pathway in mammalian oocytes. Nucleic Acids Res 48: 8050-8062. doi:10.1093/nar/gkaa543

Katoh T, Sakaguchi Y, Miyauchi K, Suzuki T, Kashiwabara SI, Baba T, Suzuki T. 2009. Selective stabilization of mammalian microRNAs by $3^{\prime}$ adenylation mediated by the cytoplasmic poly(A) polymerase GLD-2. Genes Dev 23: 433-438. doi:10.1101/gad.1761509

Kozomara A, Griffiths-Jones S. 2014. miRBase: annotating high confidence microRNAs using deep sequencing data. Nucleic Acids Res 42: D68-D73. doi:10.1093/nar/gkt1181

Kozomara A, Birgaoanu M, Griffiths-Jones S. 2019. miRBase: from microRNA sequences to function. Nucleic Acids Res 47: D155-D162. doi:10.1093/nar/gky1141

Landgraf P, Rusu M, Sheridan R, Sewer A, Iovino N, Aravin A, Pfeffer S, Rice A, Kamphorst AO, Landthaler M, et al. 2007. A mammalian microRNA expression atlas based on small RNA library sequencing. Cell 129: 1401-1414. doi:10.1016/j.cell.2007.04.040

Langmead B, Trapnell C, Pop M, Salzberg SL. 2009. Ultrafast and memoryefficient alignment of short DNA sequences to the human genome. Genome Biol 10: R25. doi:10.1186/gb-2009-10-3-r25

Lau NC, Seto AG, Kim J, Kuramochi-Miyagawa S, Nakano T, Bartel DP, Kingston RE. 2006. Characterization of the piRNA complex from rat testes. Science 313: 363-367. doi:10.1126/science.1130164

\section{Genome Research}

www.genome.org 
Law CW, Chen Y, Shi W, Smyth GK. 2014. voom: precision weights unlock linear model analysis tools for RNA-seq read counts. Genome Biol 15: R29. doi:10.1186/gb-2014-15-2-r29

Lee M, Choi Y, Kim K, Jin H, Lim J, Nguyen TA, Yang J, Jeong M, Giraldez AJ, Yang H, et al. 2014. Adenylation of maternally inherited microRNAs by Wispy. Mol Cell 56: 696-707. doi:10.1016/j.molcel.2014.10.011

Liu J, Carmell MA, Rivas FV, Marsden CG, Thomson JM, SongJJ, HammondSM, Joshua-Tor L, Hannon GJ. 2004. Argonaute2 is the catalytic engine of mammalian RNAi. Science 305: 1437-1441. doi:10.1126/science.1102513

Lund E, Liu M, Hartley RS, Sheets MD, Dahlberg JE. 2009. Deadenylation of maternal mRNAs mediated by miR-427 in Xenopus laevis embryos. RNA 15: 2351-2363. doi:10.1261/rna.1882009

Ma J, Flemr M, Stein P, Berninger P, Malik R, Zavolan M, Svoboda P, Schultz RM. 2010. MicroRNA activity is suppressed in mouse oocytes. Curr Biol 20: 265-270. doi:10.1016/j.cub.2009.12.042

Marzi MJ, Ghini F, Cerruti B, de Pretis S, Bonetti P, Giacomelli C, Gorski MM, Kress T, Pelizzola M, Muller H, et al. 2016. Degradation dynamics of microRNAs revealed by a novel pulse-chase approach. Genome Res 26: 554-565. doi:10.1101/gr.198788.115

McCallie B, Schoolcraft WB, Katz-Jaffe MG. 2010. Aberration of blastocyst microRNA expression is associated with human infertility. Fertil Steril 93: 2374-2382. doi:10.1016/j.fertnstert.2009.01.069

Meister G, Landthaler M, Patkaniowska A, Dorsett Y, Teng G, Tuschl T. 2004. Human Argonaute 2 mediates RNA cleavage targeted by miRNAs and siRNAs. Mol Cell 15: 185-197. doi:10.1016/j.molcel.2004.07.007

Mondou E, Dufort I, Gohin M, Fournier E, Sirard MA. 2012. Analysis of microRNAs and their precursors in bovine early embryonic development. Mol Hum Reprod 18: 425-434. doi:10.1093/molehr/gas015

Morita S, Horii T, Kimura M, Goto Y, Ochiya T, Hatada I. 2007. One argonaute family member, Eif2c2 (Ago2), is essential for development and appears not to be involved in DNA methylation. Genomics 89: 687696. doi:10.1016/j.ygeno.2007.01.004

Mortensen RD, Serra M, Steitz JA, Vasudevan S. 2011. Posttranscriptional activation of gene expression in Xenopus laevis oocytes by microRNA-protein complexes (microRNPs). Proc Natl Acad Sci 108: 8281-8286. doi:10 $.1073 /$ pnas. 1105401108

Murchison EP, Stein P, Xuan Z, Pan H, Zhang MQ, Schultz RM, Hannon GJ. 2007. Critical roles for Dicer in the female germline. Genes Dev 21: 682693. doi:10.1101/gad.1521307

Nakamura A, Amikura R, Hanyu K, Kobayashi S. 2001. Me31B silences translation of oocyte-localizing RNAs through the formation of cytoplasmic RNP complex during Drosophila oogenesis. Development 128: 32333242. doi:10.1242/dev.128.17.3233

Neilsen CT, Goodall GJ, Bracken CP. 2012. IsomiRs-the overlooked repertoire in the dynamic microRNAome. Trends Genet 28: 544-549. doi:10 $.1016 /$ j.tig.2012.07.005

Ohnishi Y, Totoki Y, Toyoda A, Watanabe T, Yamamoto Y, Tokunaga K, Sakaki Y, Sasaki H, Hohjoh H. 2010. Small RNA class transition from siRNA/piRNA to miRNA during pre-implantation mouse development. Nucleic Acids Res 38: 5141-5151. doi:10.1093/nar/gkq229

Ozata DM, Gainetdinov I, Zoch A, O'Carroll D, Zamore PD. 2019. PIWI-interacting RNAs: small RNAs with big functions. Nat Rev Genet 20: 89108. doi:10.1038/s41576-018-0073-3

Penzkofer D, Bonauer A, Fischer A, Tups A, Brandes RP, Zeiher AM, Dimmeler S. 2014. Phenotypic characterization of miR-92a ${ }^{-1-}$ mice reveals an important function of miR-92a in skeletal development. PLoS One 9: e101153. doi:10.1371/journal.pone.0101153

Place RF, Li LC, Pookot D, Noonan EJ, Dahiya R. 2008. MicroRNA-373 induces expression of genes with complementary promoter sequences. Proc Natl Acad Sci 105: 1608-1613. doi:10.1073/pnas.0707594105

Quinlan AR, Hall IM. 2010. BEDTools: a flexible suite of utilities for comparing genomic features. Bioinformatics 26: 841-842. doi:10.1093/bioinfor matics/btq033

Reichhardt MP, Lundin K, Lokki AI, Recher G, Vuoristo S, Katayama S, Tapanainen JS, Kere J, Meri S, Tuuri T. 2019. Complement in human pre-implantation embryos: attack and defense. Front Immunol 10: 2234. doi:10.3389/fimmu.2019.02234

Richter JD, Lasko P. 2011. Translational control in oocyte development. Cold Spring Harb Perspect Biol 3: a002758-a002758. doi:10.1101/cshper spect.a002758

Ritchie ME, Phipson B, Wu D, Hu Y, Law CW, Shi W, Smyth GK. 2015. limma powers differential expression analyses for RNA-sequencing and microarray studies. Nucleic Acids Res 43: e47. doi:10.1093/nar/ gkv007

Rosenbluth EM, Shelton DN, Sparks AET, Devor E, Christenson L, Van Voorhis BJ. 2013. MicroRNA expression in the human blastocyst. Fertil Steril 99: 855-861.e3. doi:10.1016/j.fertnstert.2012.11.001

Rueda A, Barturen G, Lebrón R, Gómez-Martín C, Alganza Á, Oliver JL, Hackenberg M. 2015. sRNAtoolbox: an integrated collection of small RNA research tools. Nucleic Acids Res 43: W467-W473. doi:10.1093/ nar/gkv555
Sheu-Gruttadauria J, MacRae IJ. 2018. Phase transitions in the assembly and function of human miRISC. Cell 173: 946-957.e16. doi:10.1016/j.cell .2018.02.051

Shibata M, Nakao H, Kiyonari H, Abe T, Aizawa S. 2011. MicroRNA-9 regulates neurogenesis in mouse telencephalon by targeting multiple transcription factors. $J$ Neurosci 31: 3407-3422. doi:10.1523/JNEUROSCI $.5085-10.2011$

Song MS, Rossi JJ. 2017. Molecular mechanisms of Dicer: endonuclease and enzymatic activity. Biochem J 474: 1603-1618. doi:10.1042/ BCJ20160759

Stein P, Rozhkov NV, Li F, Cárdenas FL, Davydenko O, Vandivier LE, Gregory BD, Hannon GJ, Schultz RM. 2015. Essential role for endogenous siRNAs during meiosis in mouse oocytes. PLoS Genet 11: e1005013. doi:10.1371/journal.pgen.1005013

Suh N, Blelloch R. 2011. Small RNAs in early mammalian development: from gametes to gastrulation. Development 138: 1653-1661. doi:10 1242/dev.056234

Suh MR, LeeY, KimJY, Kim SK, MoonSH, LeeJY, Cha KY, Chung HM, Yoon HS, Moon SY, et al. 2004. Human embryonic stem cells express a unique set of microRNAs. Dev Biol 270: 488-498. doi:10.1016/j.ydbio.2004.02.019

Suh N, Baehner L, Moltzahn F, Melton C, Shenoy A, Chen J, Blelloch R. 2010. MicroRNA function is globally suppressed in mouse oocytes and early embryos. Curr Biol 20: 271-277. doi:10.1016/j.cub.2009.12.044

Sun S, Hood M, Scott L, Peng Q, Mukherjee S, Tung J, Zhou X. 2017. Differential expression analysis for RNAseq using Poisson mixed models. Nucleic Acids Res 45: e106. doi:10.1093/nar/gkx204

Taborska E, Pasulka J, Malik R, Horvat F, Jenickova I, Jelić Matošević Z, Svoboda P. 2019. Restricted and non-essential redundancy of RNAi and piRNA pathways in mouse oocytes. PLoS Genet 15: e1008261. doi:10.1371/journal.pgen.1008261

Tang F, Kaneda M, O'Carroll D, Hajkova P, Barton SC, Sun YA, Lee C, Tarakhovsky A, Lao K, Surani MA. 2007. Maternal microRNAs are essential for mouse zygotic development. Genes Dev 21: 644-648. doi:10 $.1101 /$ gad.418707

Tesarik J, Kopecny V, Plachot M, Mandelbaum J. 1987. High-resolution autoradiographic localization of DNA-containing sites and RNA synthesis in developing nucleoli of human preimplantation embryos: a new concept of embryonic nucleologenesis. Development 101: 777-791. doi:10 1242/dev.101.4.777

Töhönen V, Katayama S, Vesterlund L, Jouhilahti EM, Sheikhi M, Madissoon E, Filippini-Cattaneo G, Jaconi M, Johnsson A, Bürglin TR, et al. 2015. Novel PRD-like homeodomain transcription factors and retrotransposon elements in early human development. Nat Commun 6: 8207. doi: $10.1038 /$ ncomms9207

Torres-Padilla ME. 2020. On transposons and totipotency. Philos Trans R Soc B Biol Sci 375: 20190339. doi:10.1098/rstb.2019.0339

Watanabe T, Totoki Y, Toyoda A, Kaneda M, Kuramochi-Miyagawa S, Obata Y, Chiba H, Kohara Y, Kono T, Nakano T, et al. 2008. Endogenous siRNAs from naturally formed dsRNAs regulate transcripts in mouse oocytes. Nature 453: 539-543. doi:10.1038/nature06908

Weick EM, Miska EA. 2014. piRNAs: from biogenesis to function. Development 141: 3458-3471. doi:10.1242/dev.094037

Williams Z, Morozov P, Mihailovic A, Lin C, Puvvula PK, Juranek S, Rosenwaks Z, Tuschl T. 2015. Discovery and characterization of piRNAs in the human fetal ovary. Cell Rep 13: 854-863. doi:10.1016/j .celrep.2015.09.030

Wyman SK, Knouf EC, Parkin RK, Fritz BR, Lin DW, Dennis LM, Krouse MA, Webster PJ, Tewari M. 2011. Post-transcriptional generation of miRNA variants by multiple nucleotidyl transferases contributes to miRNA transcriptome complexity. Genome Res 21: 1450-1461. doi:10.1101/gr.118059.110

Yan L, Yang M, Guo H, Yang L, Wu J, Li R, Liu P, Lian Y, Zheng X, Yan J, et al. 2013. Single-cell RNA-Seq profiling of human preimplantation embryos and embryonic stem cells. Nat Struct Mol Biol 20: 1131-1139. doi:10 1038/nsmb.2660

Yang Q, Lin J, Liu M, Li R, Tian B, Zhang X, Xu B, Liu M, Zhang X, Li Y, et al. 2016. Highly sensitive sequencing reveals dynamic modifications and activities of small RNAs in mouse oocytes and early embryos. Sci Adv 2: e1501482. doi:10.1126/sciadv.1501482

Yang O, Li R, Lyu O, Hou L, Liu Z, Sun O, Liu M, Shi H, Xu B, Yin M, et al. 2019. Single-cell CAS-seq reveals a class of short PIWI-interacting RNAs in human oocytes. Nat Commun 10: 3389. doi:10.1038/s41467-019$11312-8$

Zhang Y, Fan M, Zhang X, Huang F, Wu K, Zhang J, Liu J, Huang Z, Luo H, Tao L, et al. 2014. Cellular microRNAs up-regulate transcription via interaction with promoter TATA-box motifs. RNA 20: 1878-1889. doi:10.1261/rna.045633.114

Received July 2, 2020; accepted in revised form May 5, 2021. 


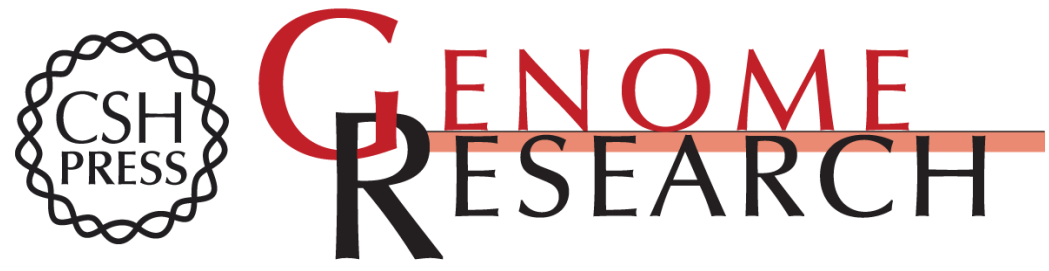

\section{Small RNA expression and miRNA modification dynamics in human oocytes and early embryos}

Pauliina Paloviita, Christel Hydén-Granskog, Dawit A. Yohannes, et al.

Genome Res. 2021 31: 1474-1485

Access the most recent version at doi:10.1101/gr.268193.120

Supplemental Material

References

Creative

Commons

License

Email Alerting Service
http://genome.cshlp.org/content/suppl/2021/07/19/gr.268193.120.DC1

This article cites 84 articles, 27 of which can be accessed free at: http://genome.cshlp.org/content/31/8/1474.full.html\#ref-list-1

This article is distributed exclusively by Cold Spring Harbor Laboratory Press for the first six months after the full-issue publication date (see https://genome.cshlp.org/site/misc/terms.xhtml). After six months, it is available under a Creative Commons License (Attribution-NonCommercial 4.0 International), as described at http://creativecommons.org/licenses/by-nc/4.0/.

Receive free email alerts when new articles cite this article - sign up in the box at the top right corner of the article or click here.

\section{Affordable, Accurate Sequencing.}

To subscribe to Genome Research go to:

https://genome.cshlp.org/subscriptions 